impairment, and the quality of the past relationship more important still.

In the light of these findings, what would be the best way to help and protect these people? It has been proposed that cases of material and physical abuse may be more successfully resolved if abuse is treated as a criminal act rather than a social problem. ${ }^{3}$ Abuse is, after all, a crime rather than a diagnosis. It is not easy to treat it as such, as shown by the experience in America, where reporting of suspected cases is mandatory in many states. ${ }^{14}$ If patients are reluctant to admit to abuse they are unlikely to press charges, and there is also the difficult question of the competence of mentally impaired patients when making allegations.

As there is no legal requirement in Britain to notify cases of abuse the usual response is to offer respite care on an inpatient or daycare basis, increase the input from formal services, and monitor the situation. If this fails, then the old person is often removed from his or her home (even when it is thought that the carer should be the one to leave). Our study would question the value of increased input of formal services to relieve abusive circumstances. Few carers expressed the desire for increased home help or district nursing input, and it was not the physical or personal aspects of caring that caused the distress; distress was caused by the socially disruptive and abusive behaviour. When this behaviour has been present for many years as an integral part of a relationship it will be very resistant to change. Efforts to change the behaviour of the patient or improve the coping skills of the carer can be made with the help of a clinical psychologist or psychogeriatrician. Carers may find carer support groups helpful, along with counselling ${ }^{1516}$ and advice on alcohol abuse. Family therapy may be of benefit. Failing this, a separation between patient and carer should be considered. Care in the community may not offer the best deal for everyone.

I thank Dr Andy Neil for his encouragement and help with setting up this study and Tamsin Wade for her great help in data collection. This study was supported by a start up grant from the British Geriatrics Society.

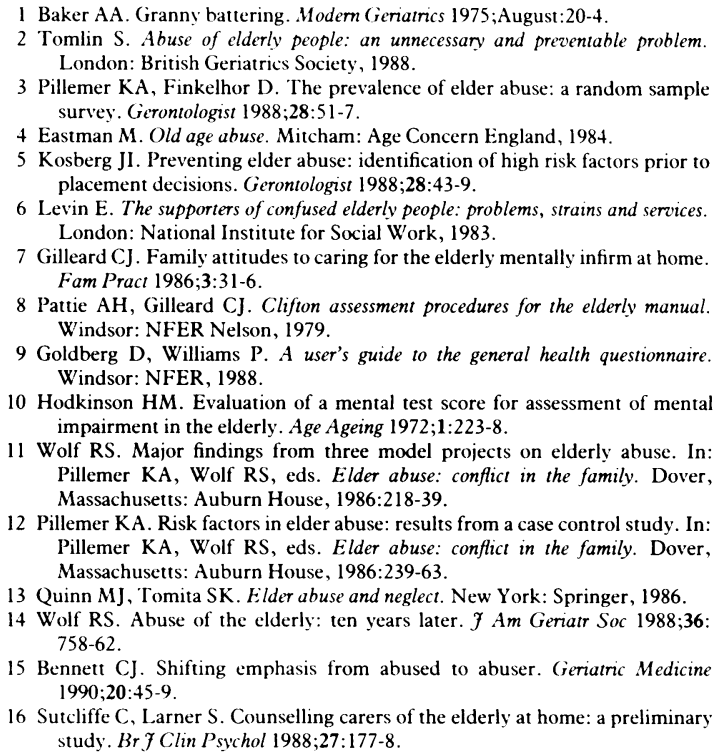
placement decisions. Gerontologist 1988;28:43-9.

6 Levin E. The supporters of confused elderly people: problems, strains and services. London: National Institute for Social Work, 1983.

7 Gilleard CJ. Family attitudes to caring for the elderly mentally infirm at home. Fam Pract 1986;3:31-6.

8 Pattie AH, Gilleard CJ. Clifton assessment procedures for the elderly manual. Windsor: NFER Nelson, 1979

9 Goldberg D, Williams P. A user's guide to the general health questionnaire. Windsor: NFER, 1988.

10 Hodkinson HM. Evaluation of a mental test score for assessment of mental impairment in the elderly. Age Ageing 1972;1:223-8.

11 Wolf RS. Major findings from three model projects on elderly abuse. In: Pillemer KA, Wolf RS, eds. Elder abuse: conflict in the family. Dover, Massachusetts: Auburn House, 1986:218-39.

12 Pillemer KA. Risk factors in elder abuse: results from a case control study. In : Pillemer KA, Wolf RS, eds. Elder abuse: confict in the family. Dover Massachusetts: Auburn House, 1986:239-63.

13 Quinn MJ, Tomita SK. Elder abuse and neglect. New York: Springer, 1986.

14 Wolf RS. Abuse of the elderly: ten years later. $\mathcal{F}$ Am Geriatr Soc 1988;36: 758-62.

15 Bennett CJ. Shifting emphasis from abused to abuser. Geriatric Medicine 1990;20:45-9.

16 Sutcliffe C, Larner S. Counselling carers of the elderly at home: a preliminary study. Br 7 Clin Psychol 1988;27:177-8.

Accepted 18 September 1990

\title{
Progression of HIV infection in misusers of injected drugs who stop injecting or follow a programme of maintenance treatment with methadone
}

\author{
Rainer Weber, Bruno Ledergerber, Milos Opravil, Walter Siegenthaler, Ruedi Lüthy
}

Division of Infectious

Diseases, Department of Medicine, University Hospital, CH-8091 Zürich, Switzerland

Rainer Weber, MD, senior registrar in internal medicine Bruno Ledergerber, PHD, consultant in biostatistics

Milos Opravil, MD, senior registrar in internal medicine Walter Siegenthaler, MD, professor of medicine, head of medical policlinic

Ruedi Lüthy, MD, professor of medicine, head of division of infectious diseases

Correspondence and requests for reprints to: Professor Lüthy.

\section{Abstract}

Objective-To see whether misusers of injected drugs who stop injecting or switch to a programme of maintenance treatment with methadone have a reduced risk of progression of HIV infection when compared with a group of persistent misusers.

Design-Observational cohort study in HIV seropositive subjects with a current or past history of misusing injected drugs.

Setting-HIV outpatient clinic at the University Hospital of Zurich, Switzerland.

Patients -297 Current and former parenteral drug misusers (median age 27) with asymptomatic HIV infection. During the observation period 80 subjects adhered to a programme of maintenance treatment with methadone, 124 continued with parenteral drug misuse, and 93 former misusers remained free of illicit drugs. No antiretroviral treatment was given during the study.

Main outcome measures-Probability of progression of HIV infection from asymptomatic to symptomatic (Centers for Disease Control stage IV) as calculated by life table analysis and compared in the three groups of patients by means of a log rank test, and predictors of disease progression as analysed with a Cox proportional hazards regression model.

Results - The 297 patients were followed up for a median of 16 months. The median duration of injecting drug misuse before enrolment was $7 \cdot 1$ years. There were no significant differences among the three groups with respect to $\mathrm{CD4}+$ counts at the beginning of the study (median $0.44 \times 10^{\%} / 1$ ). Life table analysis showed a significantly lower probability of progression of HIV disease in both the methadone treated group and former drug misusers than in persistent injecting drug misusers. Multivariate regression analysis showed a relative risk of progression of the disease of $1.78(95 \%$ confidence interval 1.20 to $2.67 ; \mathrm{p}<0.01$ ) in persistent injecting drug misusers, $0.48(0.29$ to $0.77 ; \mathrm{p}<0.01)$ in the methadone treated group, and $0.66(0.41$ to 1.06 ; $\mathbf{p}=\mathbf{0 . 0 8 5}$ ) in former drug misusers.

Conclusions-Stopping the misuse of injected drugs slows the progression of HIV disease in infected subjects. Drug treatment programmes are effective in secondary prevention of HIV associated morbidity.

\section{Introduction}

To establish strategies in the prevention and treatment of HIV infection in injecting drug misusers we need data on the natural course of HIV infection in these subjects. Despite the high incidence of AIDS among injecting drug misusers in the United States and Europe these data are rare, primarily because of 
difficulties in establishing long term follow up studies. In addition, neither the influence of continued drug injection nor the influence of drug treatment programmes on the progression of HIV disease has been well determined.

We have evaluated the progression of HIV disease in a cohort of infected subjects in Zurich with a current or past history of misusing injected drugs and sought to determine whether programmes of maintenance treatment with methadone and stopping parenteral drug misuse reduce the risk of subsequent HIV associated morbidity.

\section{Subjects and methods}

From September 1984, 297 current and former injecting drug misusers with asymptomatic HIV infection were followed up in the AIDS outpatient clinic at the University Hospital of Zurich. None had received antiretroviral treatment, and none was given any during the study. Patients had attended the clinic seeking counselling or care for HIV and non-HIV associated morbidity and volunteered to be examined at least twice a year. Visits included a medical history, physical examination, and laboratory testing. HIV infection was staged according to the system of the United States Centers for Disease Control. ${ }^{2}$ The probability of progression from asymptomatic stage II or III infection to symptomatic stage IV was calculated by life table analysis (Kaplan-Meier method) in the following three groups:

(1) Patients receiving maintenance treatment with methadone - The aim of the methadone treatment programme was the long term substitution of oral methadone for illegal injectable opiates under medical supervision. Comprehensive medical and psychosocial services were provided. Criteria for inclusion in a methadone treatment programme were definite opiate dependence, including daily injection of heroin; no cocaine abuse; willingness to submit to the requirements of the programme; and impracticability of abstinence. Methadone was prescribed by the methadone treatment services of the hospital's department of social psychiatry or by authorised general practitioners and dispensed by these agencies daily under supervision. Patients were required to cooperate in regular weekly counselling. Compliance with the programme was checked by regular screening of the urine for drugs. Patients whose results were continually positive for heroin or cocaine were removed from the programme and evaluated as persistent injecting drug misusers. The AIDS outpatient clinic neither prescribed nor dispensed methadone, so avoiding possible conflicts associated with drug treatment that might interfere with medical management.

(2) Persistent injecting drug misusers-Patients who continued with parenteral drug misuse during the study mainly injected heroin once to four times daily.
A few patients reported less than daily injection, and these patients averaged at least one injection every second day. Misuse exclusively of injected cocaine was not recorded. Occasional injecting of cocaine in addition to heroin was reported by one fifth of these patients.

(3) Former injecting drug misusers were patients not having replacement therapy who had stopped injecting drugs before the study and who remained free of illicit drugs during the study. This classification was based on repeated interviews and physical examination.

Progression rates were compared by log rank test. The Wilcoxon rank sum test was used to compare sociodemographic data. To control for cofactor effects predictors of progression of HIV infection were analysed with a backward stepwise Cox proportional hazards regression model. This analysis was performed in 197 patients, CD4+ counts not being available routinely before September 1986. Variables were persistent injecting drug misuse, former injecting drug misuse, methadone maintenance treatment programme, age, sex, interval between first misuse of injected drugs and entry to study, duration of injecting drug misuse, and (in order to control for time since HIV infection) CD4+ counts at entry to study. The time variable was the interval between the first CD4+ count and the end of the observation period.

\section{Results}

The 297 patients (191 men, 106 women; median age 27 years (range 19-50)) were followed up for a median of 16 months (range 1-58). During follow up 80 patients adhered to a methadone maintenance treatment programme, 93 remained free of illicit drugs, and 124 continued misusing injected drugs (table I). There were no significant differences among the groups in age, sex, and available CD4+ counts at study entry (median CD4+ count for all patients $0.44 \times 10^{9} / 1$, range $\left.0.01-1 \cdot 91 \times 10^{\%} / 1\right)$. The median year of first misusing injected drugs was 1979, and the median interval between first misusing injected drugs and entering the study was $7 \cdot 1$ years (range $0 \cdot 9-23$ ). The methadone treated group had begun injecting drugs significantly earlier than the other two groups and had a significantly longer follow up (table I).

The probabilities of HIV infection progressing from Centers for Disease Control stage II or III to stage IV after one, two, and three years of follow up were $2 \%$ ( $95 \%$ confidence interval $0 \%$ to $5 \%$ ), $11 \%$ (3\% to $19 \%$ ), and $29 \%(15 \%$ to $43 \%)$ in the methadone treated group; $10 \%$ ( $3 \%$ to $16 \%$ ), $21 \%$ ( $10 \%$ to $32 \%$ ), and $29 \%$ ( $14 \%$ to $43 \%)$ in former injecting drug misusers; and $11 \%(5 \%$ to $17 \%), 36 \%(24 \%$ to $48 \%$ ), and $60 \%(45 \%$ to $76 \%$ ) in persistent injecting drug misusers (figure). The progression rate in persistent injecting drug misusers was significantly higher than that in the methadone treated $(p<0.01)$ and former drug misuser groups $(p<0.05)$.

In a Cox proportional hazards regression analysis

TABLE I-Characteristics of patients in the three study groups

\begin{tabular}{lccc}
\hline & $\begin{array}{c}\text { Patients in methadone } \\
\text { treatment programme }\end{array}$ & $\begin{array}{c}\text { Former injecting } \\
\text { drug misusers }\end{array}$ & $\begin{array}{c}\text { Persistent injecting } \\
\text { drug misusers }\end{array}$ \\
$\mathrm{p} \mathrm{Value \star}$
\end{tabular}

$\star$ Wilcoxon rank sum test. 


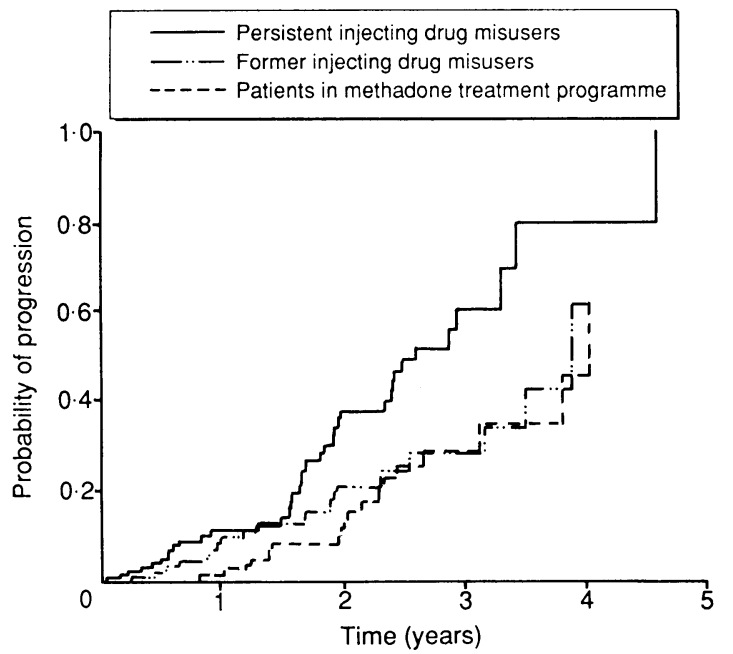

Probability of progression of HIV infection from Centers for Disease Control stage II or III to stage IV in the three patient groups

CD4+ count, continued drug use, and maintenance treatment with methadone gave independent predictive information for the progression of HIV infection. The relative risks of progression were 1.50 ( $95 \%$ confidence interval 1.35 to 1.67 ) for $50 \%$ decrease in CD4+ cells $(\mathrm{p}<0.001), 1.78(1.20$ to 2.67$)$ for persistent drug misuse $(p<0.01)$, and $0.48(0.29$ to 0.77$)$ for the methadone treatment $(\mathrm{p}<0.01)$. A trend towards slower progression was also found in former drug users (relative risk 0.66 (95\% confidence interval 0.41 to $1 \cdot 06) ;(p=0.085)$. All other variables tested (age, sex, interval between first misuse of injected drugs and entry to study, and duration of injecting drug misuse) yielded no significant predictive information and were eliminated during the backward stepwise multivariate regression analysis.

During follow up 40 patients died (table II). Twenty died of AIDS related complications (as defined by the Centers for Disease Control), ${ }^{2}$ three of bacterial pneumonia and septicaemia, 12 of a heroin overdose; one death was suicide, and four patients died of other causes. Fatal heroin poisoning occurred in 10 persistent injecting drug misusers and two patients who had returned to injecting after a drug free interval. No case of poisoning with an illicit drug occurred in the methadone treated group. The overall death rate (mainly attributable to poisoning) was significantly higher in persistent injecting drug misusers than in former drug misusers or patients given methadone.

\section{Discussion}

Acquisition and spread of HIV infection are closely linked with injecting drug misuse, ${ }^{3}$ and strategies to prevent HIV infection and stop misusers injecting overlap considerably. ${ }^{+6}$ The key question in this study was whether stopping the misuse of injected drugs

TABLE II-Causes of death among patients in the three groups

\begin{tabular}{lccrr}
\hline & $\begin{array}{c}\text { Patients in methadone } \\
\text { treatment programme }\end{array}$ & $\begin{array}{c}\text { Former injecting } \\
\text { drug misusers }\end{array}$ & $\begin{array}{c}\text { Persistent injecting } \\
\text { drug misusers }\end{array}$ & Total \\
\hline $\begin{array}{l}\text { AIDS related death } \\
\text { Bacterial pneumonia }\end{array}$ & 5 & 4 & 11 & 20 \\
$\begin{array}{l}\text { Septicaemia } \\
\text { Heroin overdose }\end{array}$ & & 1 & 1 & 2 \\
Suicide & 1 & $2+$ & 1 & 1 \\
Homicide & 1 & & 1 & 1 \\
Cirrhosis of liver & & & 1 & 1 \\
Subarachnoid haemorrhage & 7 & 7 & 26 & 1 \\
Unknown & 7 & & & 1 \\
\hline Total & & & & 40 \\
\hline
\end{tabular}

^As defined by Centers for Disease Control.

tOne patient resumed injecting drugs after release from prison and was followed up for six months. Another patien returned to injecting drugs after a drug free interval of 30 months. preserved or improved the health of misusers infected with HIV. Our data suggest that stopping injecting drug misuse lessens HIV associated morbidity in infected subjects and that appropriate treatment programmes for drug misuse may be effective in preventing HIV related complications.

Arguably the results of this non-randomised observational intervention study might be explained by confounding factors. The date of acquiring HIV infection in our study population was unknown, and therefore progression rates might have been influenced by different durations of infection. This, however, seems unlikely. The median year of first misusing injected drugs was similar in the three groups (197880 ), and sharing injecting equipment was common in Zurich until 1985. Hence the risk of acquiring HIV was similar, suggesting a comparable duration of infection. In addition, CD4+ counts, a known marker of the progression of HIV disease, ${ }^{78}$ were similar in the three groups at entry to the study. Multivariate regression analysis with CD4+ count at study entry as one of the predictor variables confirmed the different relative risks for disease progression.

Our findings are consistent with those of Des Jarlais et al, who found that continued drug injecting was associated with an increased loss of CD4+ cells in a cohort of injecting drug misusers in New York City drug treatment programmes. ${ }^{9}$ Kaslow et al found no evidence for a role of alcohol or other psychoactive drugs in accelerating immunodeficiency in HIV seropositive homosexual and bisexual men and, in addition, no relation between opiates and disease progression. ${ }^{10}$ The number of injecting drug misusers in their cohort, however, was small.

Searching for an explanation for our results includes examining the role of cofactors that may influence the progression of HIV infection. Zagury et al hypothesised that repeated antigenic stimulation of HIV infected CD4+ cells may promote expression of HIV, depletion of CD4+ cells, and further spread of the virus and consequently may affect the latency period in AIDS." In vitro studies showing that herpesviruses enhance replication of HIV, ${ }^{12}{ }^{13}$ as well as clinical observations of potentially earlier progression to AIDS in cases of coinfection with HIV and cytomegalovirus, ${ }^{14}$ suggest that such cofactors may contribute to the pathogenesis of HIV infection. ${ }^{15}$ Illicit use of injected drugs is often associated with non-sterile drug preparations, needle sharing, and potential repeated exposure to HIV and other infectious or toxic agents which might contribute to increased HIV associated morbidity. Our finding of a slower progression of HIV disease in rehabilitated drug users might be explained by the elimination of such cofactors. Available data suggest no clear immunosuppressive or HIV enhancing effect of the injected drugs themselves or other psychoactive drugs. ${ }^{1016}$

Although the influence of additional factors such as patient care, compliance with therapeutic interventions, and psychosocial aspects is difficult to measure, they may contribute to the better outcome in rehabilitated drug misusers. Patients attending a methadone maintenance treatment programme benefit from continuing medical care. This could result in earlier therapeutic interventions for intercurrent illnesses. Similarly, former drug misusers have a healthier lifestyle and usually have better and earlier access to medical care than persistent injecting drug misusers.

Many studies have shown that treatment of drug misuse, including methadone treatment programmes, can prevent the secondary psychosocial and physical morbidity of drug misuse and that social reintegration is achievable for many subjects. ${ }^{6} 17-20$ In addition, our results show that HIV associated morbidity as well as death rates can successfully be reduced. 
Furthermore, secondary prevention in HIV infected injecting drug misusers aims at another aspect: socially reintegrated patients or those enrolled in a drug treatment programme are more likely to attend educational programmes, which may limit the further spread of HIV infection. ${ }^{4617}$

We thank the staff of the methadone treatment services (Department of Social Psychiatry, Psychiatric University Hospital, University Hospital, Zurich; chairman: Professor A Uchtenhagen) for patient care and $\mathrm{K}$ Olsson for technical help. This work was supported in part by a grant from the Swiss Federal Office of Public Health.

1 Goedert JJ, Blattner WA. The epidemiology and natural history of huma immunodeficiency virus. In: De Vita VT, Hellman S, Rosenberg SA, eds. AIDS: etiology, diagnosis, treatment, and prevention. Philadelphia: Lippincott, AIDS: etiolo

2 Centers for Disease Control. Revision of the case definition for acquired immunodeficiency syndrome. MMWR 1987;36(suppl 2S):1-15S.

3 Des Jarlais DC, Friedman SR, Novick DM, et al. HIV-1 infection among intravenous drug users in Manhattan, New York City, from 1977 through 1987. FAMA 1989;261:1008-12.

4 Brickner PW, Torres RA, Barnes M, et al. Recommendations for control and prevention of human immunodeficiency virus (HIV) infection in intravenous drug users. Ann Intern Med 1989;110:833-7.

5 Centers for Disease Control. Coordinated community programs for HIV prevention among intravenous drug users-California, Massachussetts. MMWR 1989;38:369-74.

6 Cooper JR. Methadone treatment and acquired immunodeficiency syndrome. FAMA 1989;262:1664-8.

7 Goedert JJ, Biggar RJ, Melby M, et al. Effect of T4 count and cofactor on the incidence of AIDS or AIDS related condition: three year follow up of the San incidence of AIDS or AIDS related condition: three year follow

8 De Wolf F, Lange JMA, Houwelling TM, et al. Numbers of CD4+ cells and the levels of core antigen of and antibodies to the human immunodeficiency
virus as predictors of AIDS among seropositive homosexual men. F Infect Dis virus as predictors
$1988 ; 158: 615-22$
9 Des Jarlais DC, Friedman SR, Marmor M, et al. Development of AIDS, HIV seroconversion, and potential co-factors for $\mathrm{T} 4$ cell loss in a cohort of intravenous drug users. AIDS 1987;1:105-11.

10 Kaslow AR, Blackwelder WC, Ostrow DG, et al. No evidence for a role of alcohol or other psychoactive drugs in accelerating immunodeficiency in HIV-1-positive individuals. FAMA 1989;261:3424-9.

11 Zagury D, Bernard J, Leonard R, et al. Long-term cultures of HTLV-IIIinfected cells: a model of cytopathology of T-cell depletion in AIDS. Science infected cells: a

12 Skolnik PR, Kosloff BR, Hirsch MS. Bidirectional interactions between human immunodeficiency virus type 1 and cytomegalovirus. $\mathcal{F}$ Infect Dis human immunodefic

13 Davis MG, Kenney SC, Kamine J, Pagano JS, Huang ES. Immediate-early gene region of human cytomegalovirus transactivates the promoter of human immunodeficiency virus. Proc Natl Acad Sci U S A 1987;84:8642-6.

14 Bonetti A, Weber R, Vogt MW, Wunderli W, Siegenthaler W, Lüthy R. Coinfection with human immunodeficiency virus type 1 (HIV-1) and cytomegalovirus in two intravenous drug users. Ann Intern Med 1989;111: 293-6.

5 Fauci AS. The human immunodeficiency virus: infectivity and mechanisms of pathogenesis. Science 1988;239:617-22.

16 Hubbard RL, Marsden ME, Cavanaugh E, Rachal JV, Ginzburg HM. Role of drug-abuse treatment in limiting the spread of AIDS. Rev Infect Dis 1988;10:377-84

17 Sorensen JL, Batki SL, Gibson DR, Dumontet R. Purnell S. Methadone maintenance and behavioural change in seropositive drug abusers: the San Franco PACE) Gral Hotion (PACE). In: Program and abstrats of the Vinternational conference on AIDS Montreal, 1989. Ottawa: International Development Research Centre,
1989:707. (Abstract Th.D.O.5.)

18 Kleber HF, Slobetz F, Mezritz MA, eds. Medical evaluation of longterm methadone-maintenance clients. Rockville, Maryland: National Institute on Drug Abuse, 1980.

19 Kreek MJ. Health consequences associated with the use of methadone. In: Cooper JR, Altman F, Brown BS, Czechowicz D, eds. Research on the treatment of narcotic addiction: state of the art. Rockville, Maryland: National Institute on Drug Abuse, 1983:456-82.

20 Finnegan LD. Clinical, perinatal and developmental effect of methadone. In Cooper JR, Altman F, Brown BS, Czechowicz D, eds. Research on the treatment of narcotic addiction: state of the art. Rockville, Maryland: National Institute on Drug Abuse, 1983:392-443.

(Accepted 2 October 1990)
University Respiratory

Medicine Unit, City

Hospital, Edinburgh EH10

5SB

M F Fitzpatrick, MRCPI,

clinical research fellow

T Mackay, MRCP, lecturer in medicine

N J Douglas, FRCP, senior lecturer

Department of Physiology,

University of

Witwatersrand,

Johannesburg,

South Africa

H Driver, PHD, research

officer

Correspondence to:

Dr Fitzpatrick.

BrMed F 1990;301:1365-8

\title{
Salmeterol in nocturnal asthma: a double blind, placebo controlled trial of a long acting inhaled $\beta_{2}$ agonist
}

\author{
M F Fitzpatrick, T Mackay, H Driver, N J Douglas
}

Abstract

Objective-To determine whether inhaled salmeterol, a new long acting inhaled $\beta$ adrenergic agonist, reduces nocturnal bronchoconstriction and improves sleep quality in patients with nocturnal asthma.

Design-Randomised, double blind, placebo controlled crossover study.

Setting-Hospital outpatient clinics in Edinburgh.

Subjects-Twenty clinically stable patients (13 women, seven men) with nocturnal asthma, median age 39 (range 18-60) years.

Interventions-Salmeterol $50 \mu \mathrm{g}$ and $100 \mu \mathrm{g}$ and placebo taken each morning and evening by metered dose inhaler. Rescue salbutamol inhalers were provided throughout the run in and study periods.

Main outcome measures-Improvement in nocturnal asthma as measured by peak expiratory flow rates and change in sleep quality as measured by electroencephalography.

Results-Salmeterol improved the lowest overnight peak flow rate at both $50 \mu \mathrm{g}$ (difference in median values $(95 \%$ confidence interval for difference in medians) 69 (18 to 88$) 1 / \mathrm{min}$ ) and $100 \mu \mathrm{g}$ (72 (23 to 61) $1 / \mathrm{min}$ ) doses twice daily. While taking salmeterol $50 \mu \mathrm{g}$ twice daily patients had an objective improvement in sleep quality, spending less time awake or in light sleep $(-9(-4$ to -44$) \mathrm{min})$ and more time in stage 4 sleep $(26(6-34) \mathrm{min})$.

Conclusions-Salmeterol is an effective long acting inhaled bronchodilator for patients with nocturnal asthma and at a dose of $50 \mu \mathrm{g}$ twice daily improves objective sleep quality.

\section{Introduction}

Three quarters of all asthmatic patients are woken from time to time by coughing, wheezing, and breathlessness. ${ }^{12}$ This nocturnal asthma is associated with significant sleep disturbance and increased nocturnal awakenings, ${ }^{3.5}$ and often these symptoms form the patient's main complaint. Hitherto no treatment has been shown to improve sleep quality in patients with nocturnal asthma.

Treatment of nocturnal bronchoconstriction has been limited by the short duration of action of conventional inhaled bronchodilators so that the bedtime dose does not produce effective bronchodilatation at the end of the night, when bronchoconstriction is usually at its most severe. ${ }^{6}$ Many asthmatic patients cannot tolerate therapeutically effective doses of sustained release oral $\beta$ agonists ${ }^{78}$ or theophylline ${ }^{9}$ which, although effective in reducing nocturnal bronchoconstriction in patients with asthma, ${ }^{7.11}$ do not produce any objective improvement in their sleep quality. ${ }^{1213}$

Salmeterol, a new inhaled $\beta$ agonist, differs from conventional $\beta$ agonists in that it produces effective bronchodilatation for 12 hours after a single inhaled dose. ${ }^{1+}$ The object of the our study was to evaluate both subjectively and objectively the effect of inhaled salmeterol on nocturnal bronchoconstriction and sleep quality in patients with nocturnal asthma.

\section{Methods}

Twenty patients with nocturnal asthma were entered into a randomised, double blind, crossover study (mean age 39 (range 18-60) years; seven men) to 